\title{
Out, standing in the field to alleviating global poverty: 2019 Nobel Prize in Economic Sciences
}

\author{
Hồ Mạnh Toàn (Al for Social Data Lab) \\ Illustration by Hồ Hoàng Anh (School of Visual Arts, New York)
}

14-10-2019

"I am a farmer and one day I was standing in an empty field deciding what to plant when a CNN reporter asked me what I was doing out there. I sarcastically said ' I'm trying to win the Nobel Prize.' He asked, 'How can you do that, out here?' I said, 'Well, I was told in order to qualify for the prize you had to be out-standing in your field, so there I was. out-standing in my field-and he ran with that story... lol" (Source: Facebook)

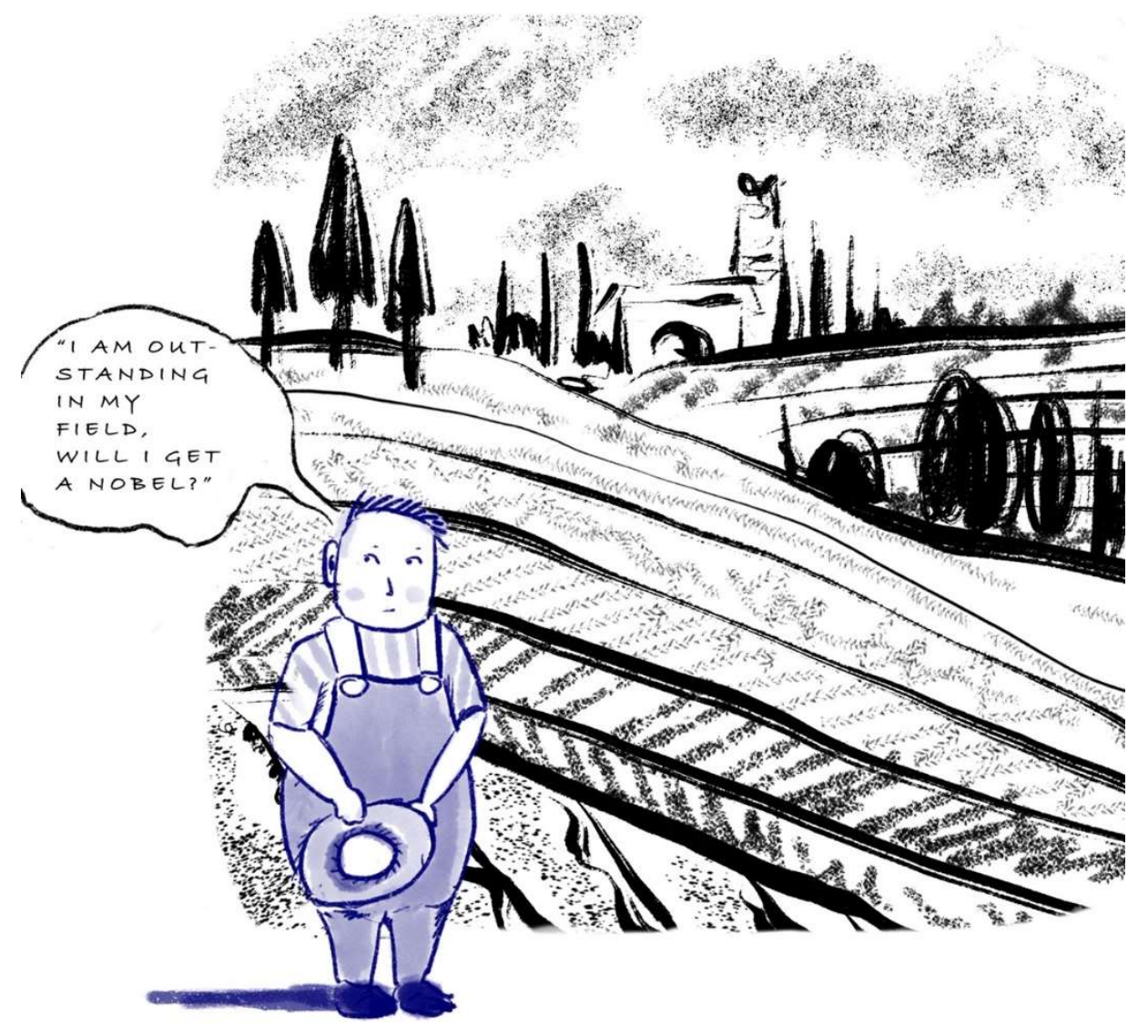

(C) Anh Hoang Ho / SSHPA 
Joking aside, 2019 Sveriges Riksbank Prize in Economic Sciences in Memory of Alfred Nobel has been awarded to Abhijit Banerjee (Massachusetts Institute of Technology, Cambridge, USA), Esther Duflo (Massachusetts Institute of Technology, Cambridge, USA) and Michael Kremer (Harvard University, Cambridge, USA) "for their experimental approach to alleviating global poverty."

Since the 1990s, the trio has developed an experimental-based approach to help us understand and fight global poverty [1]. One of their pioneer studies was in education, especially focusing on how to improve educational results with the lowest cost. By conducting field experiments with a local non-governmental organization in rural western Kenya, Michael Kremer and colleagues found that focused help for weak students brought significant educational results, while more textbooks or free meals had small effects [2]. Similar follow-up studies by Abhijit Banerjee, Esther Duflo and others in India also showed the significant effects of focusing help on weak students [3].

Even though the two latest studies from my lab focus more on book reading behavior of students in Vietnam, the empirical results identified several factors that contribute to students' STEM-educational results. Reading interests, having a clear idea about future careers, and the involvement of the mother are strong indicators of high academic achievement in STEM education [4]. Meanwhile, to effectively foster the interest in reading for children, access to a diverse bookcase both at home and school is necessary [4,5].

The contribution of this year's Laureates is not only in education but also in health, credit, and agriculture. Their microeconomic approach to development economics has reshaped the discipline and shows that sometimes, we need to be out, standing in the field to actually make a difference.

*Details of the Laureates' contribution and research can be found in the document prepared by The Committee for the Prize in Economic Sciences in Memory of Alfred Nobel [1].

NOTES: Published in EASE Vietnam SciComm System on 14 October 2019: https://sc.sshpa.com/post/5568

\section{References:}

[1] Nobel Media AB 2019. (14 Oct 2019). Advanced information. NobelPrize.org. Retrieved from https://www.nobelprize.org/prizes/economic-sciences/2019/advanced-information/

[2] Kremer M. (2003). Randomized Evaluations of Educational Programs in Developing Countries: Some Lessons. American Economic Review, 93(2), 102-106.

[3] Banerjee A, Cole S, Duflo E, \& Linden L. (2007). Remedying Education: Evidence from Two Randomized Experiments in India. Quarterly Journal of Economics, 122(3), 1235-1264. 
[4] Le TTH, Tran T, Trinh TPT, Nguyen CT, Nguyen TPT, Vuong TT, Vu TH, Bui DQ, Vuong HM, Hoang PH, Nguyen MH, Ho MT, Vuong QH. (2019). Reading habits, socioeconomic conditions, occupational aspiration and academic achievement in Vietnamese junior high school students. Sustainability, 11(18), 5113; DOI: 10.3390/su11185113.

[5] Tran T, Le TTH, Nguyen TT, Pham AG, Vu TH, Nguyen MH, Vuong HM, Hoang PH, Vuong TT, Ho MT, Vuong QH. (2019). The relationship between birth order, sex, home scholarly culture and youths' reading practices in promoting lifelong learning for sustainable development in Vietnam. Sustainability, 11(16), 4389; DOI: 10.3390/su11164389. 